\title{
THERMAL PERFORMANCE, USAGE BEHAVIOUR AND FOOD WASTE OF DOMESTIC REFRIGERATORS IN A UNIVERSITY STUDENT COMMUNITY: FINDINGS TOWARDS CITIES SUSTAINABILITY
}

\author{
DIOGO GALVÃO ${ }^{1}$, PEDRO DINIS GASPAR ${ }^{1,2}$, PEDRO DINHO DA SILVA $^{1,3} \&$ LUÍS PIRES $^{1}$ \\ ${ }^{1}$ University of Beira Interior, Rua Marquês d'Ávila e Bolama, Portugal \\ ${ }^{2} \mathrm{C}$-MAST - Centre for Mechanical and Aerospace Science and Technologies, Portugal \\ ${ }^{3} \mathrm{C}-\mathrm{MADE}$ - Centre of Materials and Building Technologies, Portugal
}

\begin{abstract}
Food safety and quality as well as storage conditions leading to food waste are related to the reduced thermal performance of domestic refrigerators, the mismanagement of food stored in it or the misuse of the equipment. This paper analyses the operative conditions of refrigerators in the student community of the University of Beira Interior (Covilhã, Portugal). A test sample of 51 appliances in the student households was instrumented with temperature dataloggers. Simultaneously, surveys on the use of refrigerator and food waste were applied to the students, ultimate users of the appliances. The students, with an average of 23 years old, mostly female $(65.9 \%)$, live alone $(6 \%)$, with their parents $(24 \%)$, or with other students $(71 \%)$. The test sample of appliances had, on average, a nominal electrical power of $126 \mathrm{~W}$ and an inner volume of 205 liters. It was found that the average storage temperature was $5.5^{\circ} \mathrm{C}$. The storage temperature in the appliances increased with the number of people who used it. This figure was largely due to improper use behaviour, in particular the number of times that the refrigerator door was open unnecessarily. The joint analysis of these data allows relating the use behaviour of with food waste. The comparison with similar studies conducted in the past shows that the average storage temperature in the current study is lower, mainly due to the technological evolution of appliances as well as the global awareness concerning food safety and food waste. The results of this work, apart from offering results about the performance of the operative conditions of refrigerators in a community not studied so far, highlights the need for further awareness of good practices to reduce food waste and simultaneously ensure food safety of the perishable food products stored in domestic refrigerators. These results could be extrapolated to the remaining people in order to develop strategies to improve cities sustainability.
\end{abstract}

Keywords: refrigerator, operative conditions, performance, student households, survey, food waste, usage behaviour.

\section{INTRODUCTION}

The need for a proper preservation of food in terms of time, safety and quality is closely related to the increasing trend of the worldwide food demand. The trend increased significantly over the last century, as well as, consequently, the number of domestic refrigerators. The technological evolution of these appliances was dictated by the need to answer the contemporary society needs. These needs are related with food safety and quality concerns, de availability of the latest technologies and to the compliance with the increasingly strict food legislation. Thus, the refrigerators technological evolution involves the improvement of the thermal performance but also of it energy efficiency. Over the past two decades, innovation, research and development studies helped increasing the energy efficiency of refrigerators [1]. Some technological improvements in refrigerators that increased the energy efficiency helped the usage behaviour, such as, the user alert when the refrigerator door is left open for too long (door opening alarms), the automatic control of the storage temperature depending on the usage type, among others [1]. 
Given the use of household refrigerators to preserve food and the witnessed technological evolution, one would expect that the food waste was marginal. However, the annual per capita food waste in Europe and USA is 95 to $115 \mathrm{~kg}$ [2], mainly originated from domestic consumption, being estimated that $60 \%$ of it can be avoided [3]. The European Parliament proposed some measures to promote the reduction of the food waste, such as labelling with double validity period (i.e., a target date of sale and a further deadline for consumption), discount on product sales that are near the expiration date, packaging size modification or the sale of unit products, among others. In fact, well-defined regulations, policies and strategies are more effective than fiscal measures in mitigating household food waste generation [4]. Beyond all these measures, it is imperative to promote the general awareness to the need to reduce the food waste. This paper aims to contribute in this sense. It describes a case study of the analysis of the performance of operative conditions of domestic refrigerators in the households of the student community of the University of Beira Interior (Covilhã, Portugal). The study involved the measurement of storage temperature and collection of the nominal electrical power and inner volume of the appliances. The storage temperature was measured by a datalogger placed in the appliance middle-shelf. Simultaneously, surveys were conducted to students to evaluate how the usage behaviour influence the thermal performance of the appliances and their information and awareness about food waste in today societies.

\section{STATE OF THE ART}

Some experimental studies have been conducted to evaluate the operative conditions of domestic refrigerators as well as to determine the concerns of users with food safety issues. The average global temperature measurements in 112 domestic refrigerators and freezers in the UK was $4.4^{\circ} \mathrm{C}$ [5]. The refrigerators operated above $5.0^{\circ} \mathrm{C}$ during $58 \%$ of the test, nevertheless representing a reduction of $2.0^{\circ} \mathrm{C}$ compared to a similar study done two decades earlier. In fact, there are benefits in terms of storage live extend and consequently in food waste reduction reducing storage temperature of the refrigerator to $4^{\circ} \mathrm{C}$ and promoting home freezing [6]-[8]. In an experimental study making use of temperature loggers placed at three shelf levels of 119 domestic refrigerators it was found that most users open the door around 20 times per day [9]. The global average storage temperature was $6.6^{\circ} \mathrm{C}$ and $80 \%$ of refrigerators had temperature above $5.0^{\circ} \mathrm{C}$. It became clear through the results analysis of a collection of studies published over the last 30 years related to the performance and utilization of domestic refrigerators, that the majority of the refrigeration equipment in the world operates at a higher storage temperature than recommended $(70 \%$ of equipment operates at a temperature higher than $5.0^{\circ} \mathrm{C}$ ) [10]. This set of studies shows the thermal behaviour of domestic refrigeration equipment in various countries over the years, concluding that there is a significant share of refrigerators in the world operating at temperature higher than the recommended, regardless of the technological evolution and informative campaigns about food safety. To determine the sensitivity of the energy consumption of refrigerators to various operational factors that reflect actual operating conditions, four different refrigerators were tested using the experimental design method Box-Behnken with three variables (room temperature, thermostat setting position and additional thermal load for hot food storage) [11]. Results show that the energy consumption of refrigerators is highly sensitive to real-life situations (variations up to $2 \mathrm{kWh}$ ). The analysis of variance (ANOVA) revealed that the room temperature is the most influential factor in the energy consumption of a refrigerator. The heat transfer inside domestic refrigerators was studied by several authors and several models were proposed to quantify heat exchange by convection, conduction and radiation in a typical refrigerator [12]-[17]. A new dynamic model for a domestic refrigerator with heat storage capacitor with SSPCM (shape-stabilized phase change materials) shows that the 
coefficient of performance, COP, increased about $19 \%$ due to latent heat stored in SSPCM [18]. The application of vacuum insulation panels (VIPs) in the refrigeration chain, incorporating them in the polyurethane (PU) foam existing on the walls of the refrigerator and freezer compartments allows potential energy savings with an investment average return of 9.7 years and 4.5 years for refrigerators and freezers respectively [19]. A review of the studies that have been published since 2008 concerning the temperature performance of refrigerators show that despite improvements in energy use, the temperature performance and use of refrigerators have not changed significantly in the last 40 years [20]. Many householders still remain unaware of the recommended refrigeration temperature range, how to ensure that the correct refrigeration temperature range is achieved, the importance of monitoring that it is being maintained, and the potential hazards of temperature abuse. While the experimental and numerical studies described above are related to the performance of refrigerators, information concerning usage procedures, attitudes and behaviours as well as the general knowledge concerning food safety was not discussed. The studies described below provide an insight on these topics. A cross-sectional study in 1178 higher education students was conducted in Kuala Lumpur (Malaysia) [21]. An online questionnaire was applied to analyze the knowledge, attitudes and behaviours related to food hygiene. The study results justify the need for a more effective educational program in creating a greater awareness of food hygiene among youth. The level of food safety knowledge in 1172 Lebanese university students was assessed trough a survey [22]. The questionnaire concerning food-handling practices consists of 16 questions related to food safety knowledge and 14 questions related to preparation practices, contamination, storage and hygiene. The results confirm the need for educational initiatives to improve the relatively low awareness on food safety between the Lebanese young adults group. For last, since the joint analysis also covers the food waste from household refrigerators, it is important to recall the research work developed on this topic. In order to suggest sustainable solutions for reducing food waste 12 tonnes of residual household waste collected from 1474 households were analysed [23]. The results showed that food waste mass increases with the number of occupants per household (household size) and the housing type. Additionally, it was determined that avoidable food waste occurred in $97 \%$ of the households, suggesting that most Danish households could avoid or at least reduce how much waste they generate. Food wasting behaviours are dependent on social, cultural, economic, and institutional factors that extent from household shopping practices, food preparation habits, use of waste management systems to food related attitudes, beliefs, and lifestyles [24]. There is not a single strategy or intervention that can meaningfully address the diverse constraints and challenges that prevent household food waste reduction. In relation to the drivers of food waste generation and behaviours and attitudes leading to food wastage, education campaigns are required focusing on the issue of food waste, quantities generated, and why it is an environmental, economic, and social concern [25], [26]. Nevertheless, these measures must be country-tailored to increase its real impact on the reduction of food waste [27]. As food systems are complex and are driven by economic, cultural and environmental factors, the potential contradictions between food policy measures can arise [28]: (1) concerns on food safety vs. food waste; (2) a higher storage temperature can be seen suited for energy saving purposes but will accelerate the degradation of the quality of products; (3) lower temperature setting would increase the energy cost, while improving food safety. Thus, there is no simple answer to improve the sustainability of food chains linking food waste prevention, energy consumption and food safety. The bibliographic review presented above allows verifying the current state of the art involving operative conditions of domestic refrigerators, food safety and food waste. However, it was shown that the information and awareness of the population is also required 
to improve refrigerators usage and reduce food waste. This study aims to contribute on this matter, providing valuable information about operative conditions and food waste knowledge and avoidance procedures obtained through in-situ households tests and surveys respectively on a community not studied so far.

\section{MATERIAL AND METHODS}

\subsection{Sample}

The student community of UBI, for the school year of 2014-2015, was composed by 6014 students (UBI's Quality Office, 2014). A value of 201 students for test sample for the existing population is obtained assuming a confidence level of $85 \%$ and a confidence interval (margin of error) of 5\% determined by Equation 1. Considering the data collected throughout this study, it is concluded that in each household inhabit on average 4 students (std. dev. $=2$ ). The refrigerators users were students with an average age of 22 (std. dev. $=2$ ), mostly female $(62 \%)$. Assuming that four students occupy each household, the optimal sample of equipment to be analyzed is 51 appliances. This sample value ensures the representability of the results and provides a reliable study

$$
n=\frac{N \cdot Z^{2} \cdot p \cdot(1-p)}{Z^{2} \cdot p \cdot(1-p)+e^{2} \cdot(N-1)}
$$

where, $n$ is the ideal sample calculated, $N$ the population in which the study is carried out, that is the number of elements in the research universe; $Z$ the standard normal variable associated to the confidence level $(Z=1.44) ; p$ the true probability of the event occur (probability of $50 \%, p=50 \%$ ); and $e$ the margin of error.

\subsection{Dataloggers}

Dataloggers of Lascar Electronics, model EL-USB-2-LCD+ were used for measurements. The dataloggers include temperature, relative humidity and dew point temperature sensors. The datalogger is a measuring device consisting of a battery, a sensor and a USB port to download the data stored in memory. The device operation is configured by software, such as the required time of measurements, values of temperature alarms (high and low), among others. The datalogger allows a wide range of configurations with regard to the desired time for measurements. The software also provides graphical visualization of the collected data, allowing overriding irrelevant data curves. After setup, the datalogger is set to start acquiring data. Once activated, the device is placed in the environment where it will acquire the data. After the measuring time, the device may be removed to transfer the data to a computer for later analysis.

\subsection{Survey details}

For the study of the operative conditions was necessary to analyze the behaviour of refrigerator users. So, two surveys were applied with different focus. The 1st survey addressed the use of the appliance, if he/she lives alone, lives with his/her parents or shares the accommodation with other students. The 2 nd survey focuses on the food waste detected during the test period. These surveys allow getting relevant information such as the number of people who uses the appliance, how these people are organized in the main meals of the 
day, and the reasons that led to the existing waste. These surveys were conducted with easy answer-type questions. They were mostly answers assessment on a scale of 0 (null) to 10 (high), or affirmation/denial (yes/no). For both surveys, the written responses were scarce.

\subsection{Collection and processing of data}

Data collection was conducted during 6 months (November to April). The procedure for data acquisition consisted on placing the datalogger in the middle height shelf of the refrigerator. In addition to the air temperature and relative humidity measurements, all the information and technical specifications of the appliances were collected in order to perform a reasonable comparison of results. The dataloggers acquired data for a minimum period of 8 days, with one-minute data acquisition rate. Thereafter, the collected data was processed (average, maximum, minimum and standard deviation values) for each appliance.

\section{ANALYSIS AND DISCUSSION OF RESULTS}

This study aims to evaluate the operative conditions performance of refrigerators used in a specific community, particularly the student community of the University of Beira Interior. A large part of the students of this university is not from the region, so they need to rent a household. To reduce costs, it is usual students to gather in-group to rent a household. Usually, the households are rent with furniture and appliances. Often, the owners put in the households to rent old appliances or purchase low-end appliances. The study takes into account variables that affect the thermal behaviour of the appliance, such as the number of people that uses it and the awareness of energy efficiency and food waste issues. This study aims to evaluate the relationship between food waste and operative conditions performance of refrigerators depending on the usage type. So, the study is completely aligned with cities sustainability concerns and the results could be extrapolated to other communities.

\subsection{Operative conditions performance}

The nominal electrical power, $P[\mathrm{~W}]$, and the capacity (volume), $V\left[\mathrm{~m}^{3}\right]$, of a refrigerator are two of the most important features. These features were extracted from appliances specifications. Fig. 1 shows a linear correlation between these two variables. The test sample appliances have an average nominal electrical power of $126 \mathrm{~W}$ (std. dev. $=59 \mathrm{~W}$ ). The average cold storage volume is 205 liters (std. dev. $=79$ liters).

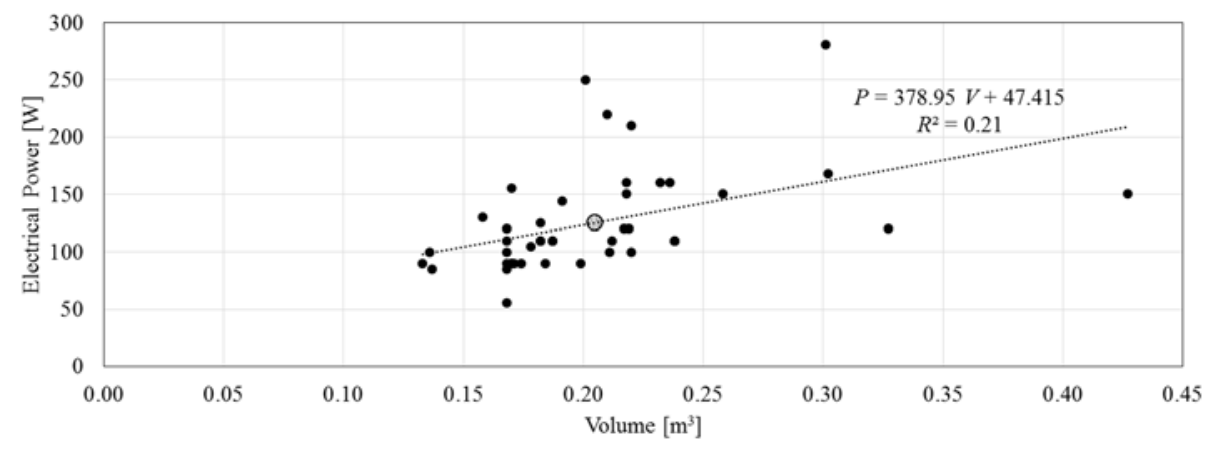

Figure 1: Correlation between volume and nominal electrical power of the test sample. 


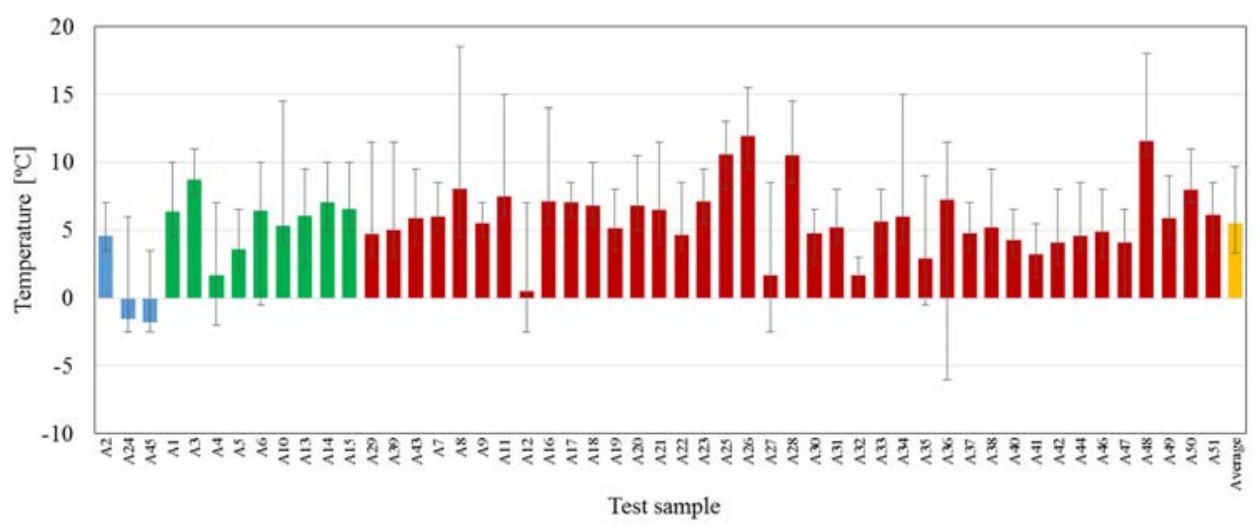

Figure 2: Avg., min. and max. values of storage temperature of the test sample.

However, the inner volumes of test sample ranged from 133 liters to 427 liters. The low value of the determination coefficient $\left(R^{2}=0.21\right)$, despite de correlation type, indicates that there is not a strong relationship between cold storage volume and the electrical power. Thus, to enable a fair comparison between the test sample devices, the specific electrical power, $p$ $\left[\mathrm{W} / \mathrm{m}^{3}\right]$ was determined. This parameter extracted from the appliance specification has an average value of $616\left[\mathrm{~W} / \mathrm{m}^{3}\right]$ with a standard deviation of $241\left[\mathrm{~W} / \mathrm{m}^{3}\right]$. Fig. 2 shows the average, minimum and maximum values of the storage temperature of each test sample appliance.

This figure also shows the overall average value and its minimum and maximum values. The different types of household sharing of students are differentiated by colors. The "blue" cases are results of students who live alone, "green" cases are results of students who live with their family, i.e., native students from Covilhã and "red" cases are results of students that share accommodation with other students. The average value is shown in "orange". The overall average value of the storage temperature is $5.5^{\circ} \mathrm{C}$. This value is $0.5^{\circ} \mathrm{C}$ above the operating limit range temperature for household refrigerators. The average operating temperature is over the higher temperature limit in $66.6 \%$ of the cases.

\subsection{Surveys}

The analysis of results obtained from answers range from how students are organized making the meals to the way as purchases of perishable products requiring refrigeration are performed. All these topics are relevant for the analysis of operative conditions performance and food waste assessment.

\subsubsection{Profile of students' accommodation sharing}

An analysis and discussion of results taking into account the profile of the accommodation sharing was developed. The results of the test students sample are divided in 3 different profiles: (1) living alone (6\%), (2) living with family (23\%), or (3) sharing accommodation with other students $(71 \%)$. Fig. 3 shows the overall average, maximum and minimum values of storage temperature for each profile of accommodation sharing. The appliances of students living alone present the lowest average storage temperature $\left(0.4^{\circ} \mathrm{C}\right)$. The factors that could lead to this situation can be related to the smaller number of times of opening the 


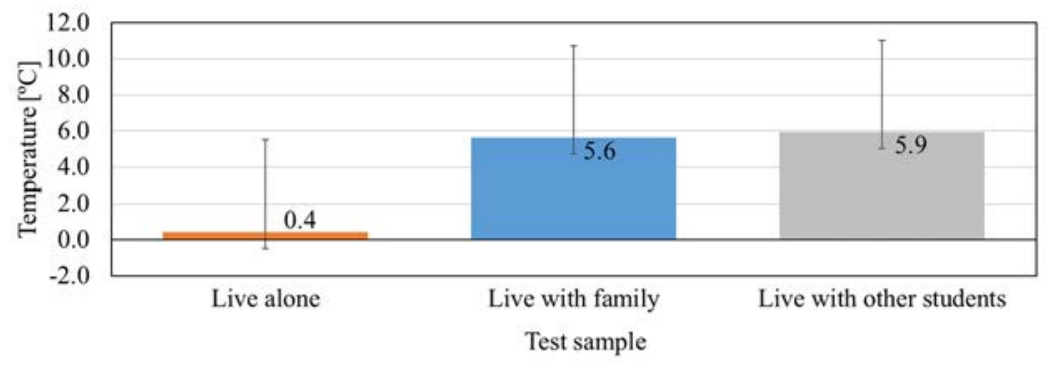

Figure 3: Avg., min. max storage temperature for each profile of accommodation sharing.

refrigerator's door, since it is only one user. The appliances located in households where students live with their parents have a higher average storage temperature than the previous situation $\left(5.6^{\circ} \mathrm{C}\right)$. For the test sample, four individuals typically compose the family. Finally, the appliances located in households shared by several students have the highest average storage temperature $\left(5.9^{\circ} \mathrm{C}\right)$. This condition arises from the household be shared by four students (or more) which implies a greater number of refrigerator's door opening. The door openings are related to the organization of the principal meals making and the distribution of each student's food products inside the appliance.

\subsubsection{College attending}

The students belong to different faculties: (1) Engineering, (2) Social Sciences (3) Health Sciences (4) Arts and Letters and (5) Science. Concerning the global average storage temperature, only the appliances used by students of the Faculties of Sciences and Arts and Letters are below the food safety threshold, $4.1^{\circ} \mathrm{C}$ and $4.2^{\circ} \mathrm{C}$, respectively. The overall average value of the maximum storage temperature reaches $6.5^{\circ} \mathrm{C}$. Conversely, the overall average values of minimum storage temperature registered was $0.0^{\circ} \mathrm{C}$. The case studies with poorer thermal operative conditions belong to students attending Faculty courses where topics of food safety, thermal performance and energy efficiency are certainly discussed. The highest average value of the storage temperature is measured in appliances of students attending the Faculty of Health Sciences. Food safety and quality topics are addressed with certainty in the courses offered at this Faculty. A similar situation occurs in the appliances of students attending the Faculty of Engineering. Topics of thermal performance and energy efficiency are taught in several course units. The appliances of students attending courses offered by the Faculties of Sciences and Arts and Letters are those with a better operative conditions performance. These results are exactly the opposite of what would be expected given the knowledge and sensitivity to these issues by the students of these colleges.

\subsubsection{Survey 1 - Survey on the use of refrigeration equipment}

The objective of this first survey is to gather information regarding the use of refrigerators by the students. The survey is composed by 10 questions, which relates to how the students use the refrigerator, the number of people who uses the equipment daily, the number of times the refrigerator door is opened, among others. Following is an analysis of the major findings from the survey.

Question 1: How do you use your refrigerator? Overall, students consider using properly the refrigerator as shown in Fig. 4. Only $6 \%$ of the student feels that uses the refrigerator in a negative way. $60 \%$ of respondents think to make very good use of the appliance. 
Question 2: How do your refrigerator preserves food? The respondents assume that none of the appliances preserves food poorly, as shown in Fig. 4. 94\% of respondents consider that their refrigerator preserves food in a positive way. Thus, there is general perception that the appliances preserve food in good conditions, that is, with low storage temperature. If Fig. 2 values are taken into account, some of the respondents have a wrong idea of the operative conditions performance provided by their refrigerator.

Question 3: How do you rate the food waste in your household? By the analysis of Fig. 4, it can be concluded that food waste is reduced. Only $20 \%$ of students consider wasting too much food. So, it can be concluded that most of students try to avoid food waste.

Question 4: How your appliance affects the household energy consumption? As shown in Fig. 4, there is no consistent opinion of students. Overall, they consider that the refrigerator has a medium effect on the household energy consumption.

Question 5: How are organized the main meals (lunch and dinner) in the household? As shown in Fig. 5, the students organize themselves in one of the three following ways: (1) alone, (2) into several groups or (3) all together. The way the students are organized in main meals influences the operative conditions performance of the refrigerator due to the amount of times the door(s) of the refrigerator is(are) open prior to meals for it preparation. $63 \%$ of respondents do not organize their meals alone. This answer is related to the average time that the refrigerators doors remain open.

Question 6: If you answered several groups indicate how many. This question is related to the previous aiming to determine the number of groups set up to prepare the main meals. From the analysis of Fig. 5, the majority of students organized themselves into two groups. It is noticeable that the organization of main meals into three groups of students will incur in more time that the refrigerator door will be open and consequently a worse operative condition performance will be reached.

Question 7: Is your refrigerator's door opened often? This question intends to investigate if students are aware of the implications on the operative condition performance due to time that the refrigerator's door remain open. As shown in Fig. 6, it is concluded that $67 \%$ of students considers that open the refrigerator's door more times than necessary throughout the day.

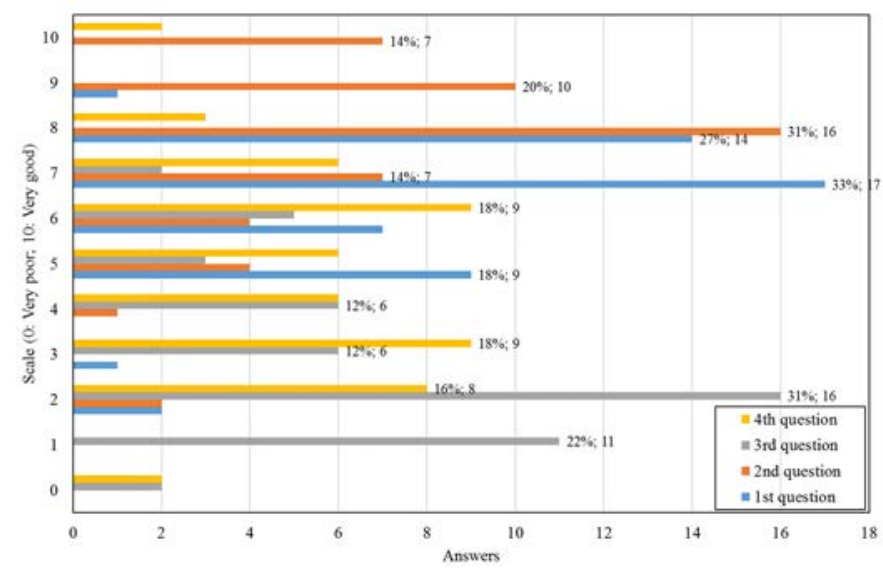

Figure 4: Survey 1 - Answers to questions 1, 2, 3 and 4. 


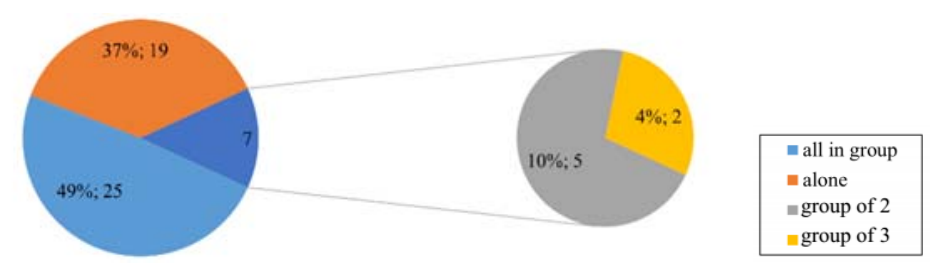

Figure 5: Survey $1-$ Answers to questions 5 and 6.

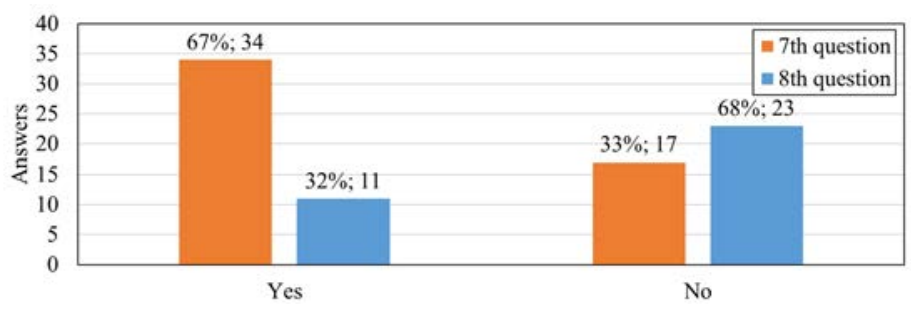

Figure 6: Survey 1 - Answers to questions 7 and 8.

Question 8: Do you think that the all refrigerator's door opening was necessary? However, as shown in Fig. 6, only 32\% of respondents consider that the all times that the refrigerator's door was open for necessity. The remaining $68 \%$ are aware the refrigerator's door was open too much. These two issues allow concluding that there is a negative perceived behaviour by most students. This behaviour can be easily changed, by raising the awareness of students concerning the negative effects of opening the refrigerator's door more than necessary.

Question 9: How many times had you changed the thermostat setting throughout the year? About half of respondents change the thermostat setpoint once in a year and $4 \%$ of students regulate the refrigerator thermostat setpoint many times over the year.

Question 10: How many people on a daily basis uses the refrigerator? As shown in Fig. 7, 65\% of the answers indicate that 3 to 5 persons use the refrigerator. However, $28 \%$ of answers indicate only 1 or 2 refrigerator users.

The data collected in this survey allows characterizing the appliances usage by students and relating the results with the experimental data of the operative conditions performance. The second survey aimed to analyze the food wasted by the students at the end of test period. It is constituted by four questions related to the amount and possible reasons for the food waste, the average number of times of the opening the refrigerator's door and a conscientious analysis of the refrigerator use during the test period. The major findings are:

Question 1: How do you evaluate the food waste during the test period? The purpose of this question is to evaluate the food waste in the households of the students when they are aware of the consequences of this situation. There was not a large food waste during the test period. Therefore, the information and awareness to the food waste issue when placing the dataloggers help students to manage the food in their refrigerator in order to reduce it.

Question 2: How did you use the refrigerator during the test period? The goal of this question is to assess the behaviour of students using the refrigerator during the test period when they are informed and aware of best practices. $91 \%$ of respondents indicate having used the refrigerator correctly. So, this question aims to evaluate whether the awareness provided 


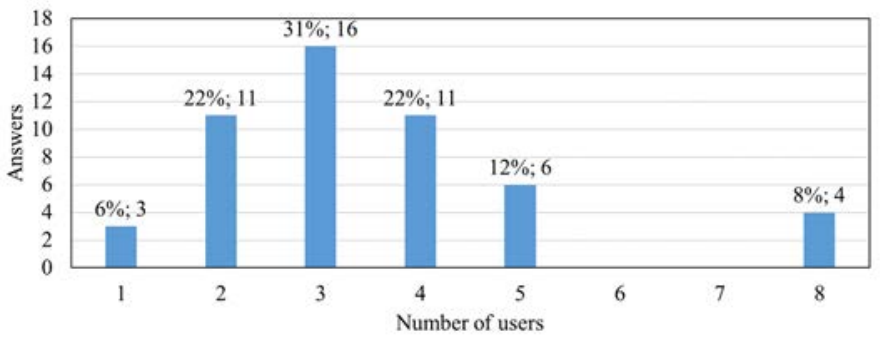

Figure 7: Survey 1 - Answers to question 10.

by this experimental study allowed the change of habits and the application of good practices leading to a better operative conditions performance and less food waste.

Question 3: What was the main reason for the food waste? The main reasons for food waste are: $\left(1^{\text {st }}\right)$ Mismanagement of food or during meals preparation that led to food waste $(27 \%) ;\left(2^{\text {nd }}\right)$ Expiration date of foods passed $(25 \%) ;\left(3^{\text {rd }}\right)$ Food forgotten in the refrigerator $(10 \%) ;\left(4^{\text {th }}\right)$ Other reasons.

Question 4: How often have you opened the refrigerator's door per day? Comparing the with results prior to the information and awareness gain of food waste issue, it can be concluded that most students gain good habits when it comes to opening the refrigerator's door ( $68 \%$ between 6 and 8 openings).

From the global analysis of the answers provided by respondents to the second survey, it is clear that informing and highlighting the food waste issues to the population will promote awareness and a concern culture. This condition may be accomplished by a broader communication plan, making use of print media, the internet and other media, with specific measures concerning household food waste-prevention [31], [32]. An effective communication and a deep involvement of government parties (national and regional) should be proposed in order to raise awareness within society and promote the reduction of waste food. In this context, the development of a communication and dissemination plan conveniently structured and coordinated among all stakeholders is a fundamental key point. The communication plan should include information materials: flyers, brochures and leaflets to distribute to the population; outreach and awareness actions through media services as journal, radio and television, and by information sessions.

\section{CONCLUSIONS}

The high levels of food waste are a global concern. Its largest share is found in households, where more than $50 \%$ could be avoided. The most of food waste at household level occur in domestic refrigerators. The factors leading to this waste result from the thermal performance of the appliance, the mismanagement of food stored-in and misuse of the appliance. This study describes the evaluation of the operative conditions of refrigerators used by the student community at the University of Beira Interior (Covilhã, Portugal). The experimental study monitored the cold storage temperature on a sample of 51 appliances. The sample devices have an average electric power of $126 \mathrm{~W}$ and average inner volume of 205 liters $(0.205 \mathrm{~m} 3)$. The overall average value of the cold storage temperature is $5.5^{\circ} \mathrm{C}$. It can be concluded that the overall operative thermal conditions surpass the upper temperature limit by a small margin $\left(0.5^{\circ} \mathrm{C}\right)$. This temperature higher than the reference level for ensuring adequate food safety may incur risks to the public health. This figure is largely related with improper behaviour of students, in particular, by the large number of times that the refrigerator is 
opened unnecessarily, thereby causing an increase in the thermal load by ambient air infiltration. The practice to reduce this condition consists in information and awareness of users about the negative usage procedures of the appliance and describing how these procedures can be corrected, and consequently improving the thermal performance, ensuring temperature values within a range for a proper food quality and safety. The comparison of the experimental results with the results of similar studies developed in several countries allows concluding that the values are very similar, although it is perceptible the influence of the technological evolution of the appliance in the overall improvement of the thermal operation.

Two surveys were conducted to evaluate how students use the refrigerator and to assess the food waste after the information and awareness provided when the dataloggers were placed inside the refrigerator to evaluate the operative conditions performance. The results show how students use the refrigerator and manage foods and meals. It also show the knowledge gain concerning food waste and energy efficiency by the information and awareness provided. This study. Additionally, provides experimental results on the thermal performance of refrigerators in a community not studied so far, intending to contribute as a reminder of the good practices for reducing food waste, while ensuring food safety of perishables food products. These results could be extrapolated to the remaining community in order to develop strategies to improve cities sustainability.

\section{REFERENCES}

[1] Bansal, P., Vineyard, E. \& Abdelaziz, O., Advances in household appliances - A review. Applied Thermal Engineering, 31, pp. 3748-3760, 2010.

[2] EU, Parliament calls for urgent measures to halve food wastage in EU. European Parliament News. Press release. Reference No: 20120118IPR35648, 2012.

[3] FAO, Global food losses and food waste - Extent, causes and prevention. Food and Agriculture Organization (FAO) of the United Nations, Rome, 2011.

[4] Chalak, A., Abou-Daher, C., Chaaban, J. \& Abiad, M.G., The global economic and regulatory determinants of household food waste generation: A cross-country analysis. Waste Management, 48, pp. 418-422, 2016.

[5] Evans, J.A., Foster, A.M. \& Brown, T., Temperature control in domestic refrigerators and freezers. In Proc. 3rd IIR ICCC. London, UK, June 23-25, 2014.

[6] Brown, T., Hipps, N.A., Easteal, S., Parry, A. \& Evans, J.A., Reducing domestic food waste by lowering home refrigerator temperatures. Int J Refrig, 40, pp. 246-253, 2014.

[7] Brown, T., Hipps, N.A., Easteal, S., Parry, A. \& Evans, J.A., Reducing domestic food waste by freezing at home. Int J Refrig, 40, pp. 362-369, 2014.

[8] Azevedo, I. et al., Incidence of Listeria spp. in domestic refrigerators in Portugal. Food Control, 16, pp. 121-124, 2005.

[9] Laguerre, O., Derens, E. \& Palagos, B., Study of domestic refrigerator temperature and analysis of factors affecting temperature: a French survey. Int $J$ Refrig, 25, pp. 653659, 2002.

[10] James, S.J., Evans, J. \& James, C., A review of the performance of domestic refrigerators. Journal of Food Engineering, 87, pp. 2-10, 2008.

[11] Geppert, J. \& Stamminger, R., Analysis of effecting factors on domestic refrigerators' energy consumption in use. Energ Convers Manage, 76, pp. 794-800, 2013.

[12] Laguerre, O., \& Flick, D., Heat transfer by natural convection in domestic refrigerators. Journal of Food Engineering, 62(1), pp. 79-88, 2004. 
[13] Laguerre, O., Ben Amara, S., Charrier-Mojtabi, M.C., Lartigue, B. \& Flick, D., Experimental study of air flow by natural convection in a closed cavity: Application in a domestic refrigerator. Journal of Food Engineering, 85(4), pp. 547-560, 2008.

[14] Ben Amara, S. et al. (2008). PIV measurement of the flow field in a domestic refrigerator model: Comparison with 3D simulations. International Journal of Refrigeration, 31(8), 1328-1340, 2008.

[15] Laguerre, O., Ben Amara, S. \& Flick, D., Numerical simulation of simultaneous heat and moisture transfer in a domestic refrigerator. Int J Refrig, 33(7), 1425-1433, 2010.

[16] Laguerre, O., \& Flick, D., Temperature prediction in domestic refrigerators: Deterministic and stochastic approaches. Int J Refrig, 33(1), pp. 41-51, 2010.

[17] Zhang, C. \& Lian, Y., Conjugate heat transfer analysis using a simplified household refrigerator model. Int J Refrig, 45, pp. 210-222, 2014.

[18] Cheng, W. \& Yuan, X., Numerical analysis of a novel household refrigerator whit shape-stabilized PCM heat storage condensers. Energy, 59, pp. 265-276, 2013.

[19] Hammond, E.C. \& Evans, J.A., Application of vacuum insulation panels in the cold chain - Analysis of viability. Int J Refrig, 47, pp. 58-65, 2014.

[20] James, C., Onarinde, B.A. \& James, S.J., The use and performance of household refrigerators: A review. Compr Rev Food Sci Food Saf, 16(1), pp. 160-179, 2017.

[21] Lowa, W.Y. et al., Determinants of food hygiene knowledge among youths: A crosssectional online study. Food Control, 59, pp. 88-93, 2016.

[22] Hassana, H.F. \& Dimassib, H., Food safety and handling knowledge and practices of Lebanese university students. Food Control, 40, pp. 127-133, 2014.

[23] Edjabou, M.E., Petersen, C., Scheutz, C. \& Astrup, T.F., Food waste from Danish households: Generation and composition. Waste Manag, 52, pp. 256-268, 2017.

[24] Parizeau, K., von Massow, M. \& Martin, R., Household-level dynamics of food waste production and related beliefs, attitudes, and behaviours in Guelph, Ontario. Waste Manag, 35, pp. 207-217, 2015.

[25] Thyberg, K.L., \& Tonjes, D.J., Drivers of food waste and their implications for sustainable policy development. Resources, Conservation and Recycling, 106, pp. 110-123, 2016.

[26] Priefer, C., Jörissen, J. \& Bräutigam K.R., Food waste prevention in Europe - A cause-driven approach to identify the most relevant leverage points for action. Resour Conserv Recy, 109, pp. 155-165, 2016.

[27] Campoy-Munoz, P., Cardenete, M.A. \& Delgado, M.C., Economic impact assessment of food waste reduction on European countries through social accounting matrices. Resour Conserv Recy, 122, pp. 202-209, 2017.

[28] Guillier, L. Duret, S. Hoang, H.M., Flick, D., Nguyen-Thé, C. \& Laguerre, O., Linking food waste prevention, energy consumption and microbial food safety: the next challenge of food policy? Current Opinion in Food Science, 12, pp. 30-35, 2016.

[29] Mathews. P., Sample Size Calculations: Practical Methods for Engineers and Scientists. Mathews Malnar and Bailey, Inc., 2010.

[30] Kresyszig, E., Advanced Engineering Mathematics, 9th ed., Willey \& Sons, Inc., 2006.

[31] Schmidt, K., Explaining and promoting household food waste-prevention by an environmental psychological based intervention study. Resour Conserv Recy, 111, pp. 53-66, 2016.

[32] Delley, M. \& Brunner, T.A., Foodwaste within Swiss households: A segmentation of the population and suggestions for preventive measures. Resour Conserv Recy, 122, pp. 172-184, 2017. 